have been mentioned in the Russian literature, but which were not adjudged by a conference on geochemical methods of prospecting for petroleum and natural gas (Neftyanoye Khozyaistvo, 1955) to be of proved usefulness, are not considered.

Each method is described in the logical order of theoretical basis, field procedure, analytical techniques and interpretation of results. The equipment for various alternative sampling and analytical techniques is described in detail. Although, in general, more comment on the relative merits of the methods and techniques would have been appreciated, the authors do not hesitate to criticize those methods, whether Russian or American, with which they do not agree on theoretical grounds.

Mention is made on a number of occasions of the difficulties of distinguishing true anomalies from false anomalies resulting from biological activity and other causes. The interpretation of leakage dispersion patterns is dependent on a considerable number of variables, yet this aspect of the subject is only relatively briefly discussed. The inclusion of additional case histories presenting all the data, their inter. pretation and the results of subsequent drilling would have been of great interest.

The authors consistently emphasize the necessity for correlating the data from different types of geochemical methods and the results of these methods with geophysical and geological information. Geochemical methods of prospecting and exploration are not a universal panacea but are additional tools in the hands of the geologist. The geochemical prospecting methods described in this book are considered to have proved their worth under certain conditions but, as with all methods of prospecting, their application is limited to those areas where conditions are favourable.

Despite some few shortcomings, this book gives a well-balanced picture of the application of geochemical techniques and is recommended to petroleum geologists interested in obtaining a knowledge of these new and rapidly developing methods, which may give valuable additional information in the search for oil deposits.

JoHN S. TOOMS

\section{GROWTH OF PRIMARY EDUCATION}

\section{Primary Education}

Suggestions for the Consideration of Teachers and Others concerned with the Work of Primary Schools. Pp. xiii +334. (London: H.M. Stationery Office, 1959.) 10s. net.

\footnotetext{
THE development of efficient methods of teaching in primary schools, improved organization of the schools themselves, and a markedly greater degree of achievement by the children have resulted from a widespread and quickening interest in primary work by teachers and the general public. This is well brought out in this Ministry of Education publication, which shows that the rise in children's achievements has not come about suddenly or by mechanical application of any special methods or practice, but because teachers, from their experience and from the growing body of research available to them, have come to understand better the ways in which children learn, and have applied their knowledge to good purpose.
}

The book is in effect an anthology of the ideas and practices which present-day teachers are successfully developing in the schools.

Twenty years ago junior schools were only tentatively striking out towards what is now common practice. Less than half the children between eight and twelve years of age were in schools separate from those containing older children also. Now, more than nine-tenths of school children up to eleven years of age are in separate infants schools, separate junior schools, or schools for children between five and eleven only.

'Primary Education' calls for a more critical consideration by teachers of the quality and substance of what is offered to the children for their learning, and for a firmer realization that children's capacities, whether small or great, should be exercised to the full.

For the man of science, one of the most interesting sections is that concerned with the teaching of mathematics. There is little doubt that deficiencies in the primary school must bear considerable responsibility for subsequent failures in mathematics. Teachers in primary schools can do much to prevent the positive dislike of mathematics which is so common in older children. It is to be hoped that the new three-year training college courses will produce primary school teachers who can get away from teaching mathematics by rote and will be able to teach young children in a meaningful way.

\section{CONURBATIONS OF GREAT BRITAIN}

\section{The Conurbations of Great Britain}

By T. W. Freeman. With a chapter on the Scottish Conurbations by Catherine $\mathrm{P}$. Snodgrass. Pp. xii +393 (66 maps). (Manchester : The University Press, 1959.) 37s. 6d. net.

$\mathrm{P}$ ATRICK GEDDES' term 'conurbation', more narrowly defined by Fawcett, is a vitally important but vague geographical concept that calls for searching analysis of criteria and their cartographic representation. For this reason we tum to this book with special interest.

As to content, Chaps. 1 and 12 should be read first. Then those of the intervening chapters about the conurbations (or the ensemble of minor conurbations) of most interest should be read. For the book is heavy in topographical detail that becomes irksome in spite of the aid of maps. The sectional treatment of each conurbation includes physical features, historical growth, distribution and movements of population, and, a main feature, the growth of the patterns of administrative areas. The work depends on geographical and historical studies as well as on the interesting data contained in reports of past commissioners and the census reports. It contains 66 maps, 25 of which show the changing patterns of the administrative areas in each conurbation.

Freeman, following Fawcett, has attempted to define every conurbation by the extent of its built-up area. There are seven major conurbations, each of which receives a separate chapter in the book. Fourteen minor conurbations have 250,000-750,000 inhabitants. These include several 'clusters' of 